Original article

\title{
Hypotensive and vasorelaxant effect of Diapocynin in normotensive rats
}

\author{
Simone R. Potje ${ }^{\mathrm{a}, \mathrm{b}, 1}$, Jéssica A. Troiano ${ }^{\mathrm{a}, \mathrm{b}, 1}$, Murilo E. Graton ${ }^{\mathrm{a}, \mathrm{b}, 1}$, Valdecir F. Ximenes ${ }^{\mathrm{c}}$, \\ Ana Claúdia M.S. Nakamune ${ }^{\mathrm{a}, \mathrm{b}}$, Cristina Antoniali ${ }^{\mathrm{a}, \mathrm{b}, *}$ \\ a Programa de Pós-graduaçao Multicêntrico em Ciências Fisiológicas, SBFis, Sao Paulo State University (UNESP), Araçatuba, Sao Paulo, Brazil \\ b Department of Basic Sciences, School of Dentistry, Sao Paulo State University (UNESP), Araçatuba, Sáo Paulo, Brazil \\ c Department of Chemistry, Faculty of Sciences, Sao Paulo State University (UNESP), Bauru, Sao Paulo, Brazil
}

\section{A R T I C L E I N F O}

\section{Keywords:}

Apocynin

Diapocynin

Hypotension

Vasodilatation

\begin{abstract}
A B S T R A C T
Nicotinamide adenine dinucleotide phosphate oxidase (NAD(P)H-oxidase) is a multicomponent enzyme system that generates superoxide anion by one-electron reduction of molecular oxygen and represents the major source of reactive oxygen species (ROS) in the vascular cells. Apocynin has been extensively used as an inhibitor of NADPH oxidase (NOX) in phagocytic cells and as an antioxidant in non-phagocytic cells. In phagocytes cells, due to the presence of myeloperoxidase, apocynin can be the converted to diapocynin, which is supposed to be the active form of this phytochemical. Moreover, apocynin was shown to induce hypotension and vasodilatation in many experimental animal models. However, there are no studies showing the effects of diapocynin on blood pressure or in vascular cells. In this present study, we used chemically synthesized diapocynin and analyzed its antioxidant capacity, effect on blood pressure and vascular reactivity. Moreover, it was evaluated the levels of nitric oxide (NO), ROS and calcium in aortic endothelial cells stimulated by diapocynin. All results were compared to apocynin. We found that diapocynin showed higher antioxidant capacity than apocynin. Apocynin and diapocynin, promoted hypotensive effects without changing the heart rate, however the effects of diapocynin were reversed faster than the effects of apocynin, which was long lasting. Diapocynin and apocynin induced endothelium dependent and independent vasodilatation, but diapocynin was less potent than apocynin regarding the capacity of induction of vasodilatation in mesenteric resistance arteries and aorta from Wistar rats. The relaxation induced by apocynin or diapocynin involves SGC and potassium channels in vascular smooth muscle cells and NOS participates of relaxation induced by apocynin or diapocynin in intact mesenteric rings. Apocynin and diapocynin increased NO and decreased ROS levels in endothelial cells, however diapocynin did not alter calcium levels in these cells. In conclusion, these results demonstrated that, similarly to apocynin, diapocynin also induces hypotensive and vasodilator effects in rats and vascular endothelium improves the diapocynin vasodilator effects by increases NO bioavailability.
\end{abstract}

\section{Introduction}

Reactive oxygen species (ROS) are chemically reactive molecules derived from molecular oxygen, partly formed as a natural byproduct of aerobic metabolism pathways and partly due to activation of membrane-bound enzyme systems in mammalian cells [1-3]. In the cardiovascular system, ROS may play a physiological or pathophysiological effect, depending on its concentration. In physiological conditions, low concentrations of ROS act as a critical second messenger in a variety of intracellular signaling pathways, regulating vascular smooth muscle cell contraction and relaxation [4-7]. However, under pathological conditions, the excess of ROS overwhelms endogenous antioxidant system and contribute to several cardiovascular diseases including atherosclerosis, hypertension, endothelial dysfunction, ischemic heart disease, arrhythmias, cardiomyopathy, and congestive and chronic heart failure $[1,8]$.

There are several sources of ROS in cardiovascular system including xanthine oxidase [9], cyclooxygenase, cytochrome P450 [10], uncoupled endothelial nitric oxide synthase (eNOS) [11], and the enzymatic complex nicotinamide adenine dinucleotide phosphate oxidase (NAD(P)H oxidase) [12], which is the main source of ROS in vascular cells. NADPH oxidase have been described in phagocytic and nonphagocytic cells and plays an important role in nonspecific host defense during infection by catalyzing the reduction of one-electron of molecular oxygen to form superoxide anion $\left(\mathrm{O}_{2}{ }^{-}\right)$[8]. In phagocytic cells, $\mathrm{NAD}(\mathrm{P}) \mathrm{H}$ oxidase is formed by a membrane associated cytochrome that

\footnotetext{
*Correspondence to: Faculdade de Odontologia de Araçatuba - UNESP, Departamento de Ciências Básicas, Rua José Bonifácio 1193, CEP 16015-050 Araçatuba, SP, Brazil.

E-mail address: crisant@foa.unesp.br (C. Antoniali).

${ }^{1}$ These authors contributed equally to this study.
} 
comprises a major component (gp91phox) and a minor component (p22phox). There are cytosolic regulatory subunits (p47phox, p67phox, p40phox and a protein GTPase Rac 2) that are required for activation of the enzyme [13]. In non-phagocytic cells, including vascular cells, diverse homolog of gp91phox (Nox2) have been identified leading to the NOX family (Nox1-Nox5, Duox1, and Duox2) [12,14].

Apocynin impairs the translocation of the p47phox [15-17], the cytosolic component of the NAD(P)H oxidase complex to the membrane in cells and has been used as $\mathrm{NAD}(\mathrm{P}) \mathrm{H}$ oxidase inhibitor in phagocytic $[18,19]$ and non-phagocytic cells $[17,20,21]$. In phagocytic cells, apocynin is converted into its active dimer diapocynin by myeloperoxidase (MPO) [22-24]. In peripheral blood, mononuclear cells (PBMC) stimulated by lipopolysaccharide, apocynin did not inhibit the production of tumor necrosis factor-alpha and interleukin-10, but diapocynin had a pronounced effect on both. Furthermore, while diapocynin efficiently inhibited gp91phox RNA expression, the same effect was only obtained for apocynin at higher [25]. In addition, as MPO is not expressed in non-phagocytic or vascular cells, the molecular mechanisms of apocynin mediated NOX inhibition in these cells is not fully understood.

It was suggested that hydrogen peroxide $\left(\mathrm{H}_{2} \mathrm{O}_{2}\right)$ may convert apocynin to diapocynin [23], or furthermore, apocynin might be an antioxidant in the vascular cells [26]. Previous studies showed neuroprotective effects of diapocynin in a pre-clinical animal model of Parkinson's disease by attenuating oxidative damage and neuroinflammatory responses [27]. Moreover, in dystrophic myotubes, diapocynin was able to inhibit ROS production [28]. Apocynin has anti-hypertensive effect in different models of hypertension [29-32] and vasodilator effects $[33,34]$. On the other hand, there are no studies showing the effects of diapocynin on blood pressure or in vascular cells. Our hypothesis is that diapocynin induces greater effects than apocynin on blood pressure and in vascular cells. Then, the aim of this study was to evaluate the in vivo and in vitro effects of synthesized diapocynin in normotensive Wistar rats and compare its effects with apocynin.

\section{Material and methods}

The experiments conducted in this study were previously approved by Animal Research Ethics Committee at the School of Dentistry of Araçatuba - UNESP (CEUA 2016-00211).

\subsection{Animals}

In this study, male normotensive Wistar rats $(n=30)$ at threemonths old $(250 \mathrm{~g})$ were used. Fifteen animals $(n=15)$ were used to perform in vivo experiments. Ten separate animals $(n=10)$ were also used in functional experiments of vascular reactivity, and the aortic and mesenteric artery rings were removed from the same animal. In flow cytometry experiments, endothelial cells were removed from aortas of five animals $(n=5)$. All animals received standard chow and water ad libitum and were kept under controlled temperature $\left(24 \pm 2{ }^{\circ} \mathrm{C}\right)$ and in a 12-h light/dark cycle.

\subsection{Biochemical analysis}

\subsubsection{Apocynin and diapocynin total antioxidant capacity}

The total antioxidant capacities were assessed by ferric reducing antioxidant power (FRAP) assay [35]. The method is based on reducing the ferric complex tripiridil triazine ( $\mathrm{Fe}^{3+} \mathrm{TPTZ}$ ) to form $\mathrm{Fe}^{2+}$ in acidic medium. Apocynin and diapocynin were diluted in dimethyl sulfoxide at $0.1 \mathrm{~mol} / \mathrm{L}$, and then, diluted in distilled water to obtain the concentrations of $0.01,0.1,1,10,100$ and $1000 \mu \mathrm{mol} / \mathrm{L}$. Fifteen microliters $(15 \mu \mathrm{L})$ of all concentrations were individually included in working solution, in duplicate, for $30 \mathrm{~min}$ at $37^{\circ} \mathrm{C}$ in the dark. The absorbance was determined at $595 \mathrm{~nm}$ (Hitachi U1100 spectrophotometer, Tokio, Japan) using a standard curve of $\mathrm{FeSO}_{4}$. The results were expressed in mmol/L $\mathrm{FeSO}_{4}$. The working solution was prepared with a mixture of 2,4,6-tripyridyl-s-triazine $10 \mathrm{mmol} / \mathrm{L}$ in $\mathrm{HCl} 40 \mathrm{mmol} / \mathrm{L}$, acetate buffer $300 \mathrm{mmol} / \mathrm{L}$ and $\mathrm{FeCl}_{3} 20 \mathrm{mmol} / \mathrm{L}, 10: 1: 1$ respectively.

\subsection{In vivo studies}

2.3.1. Cannulation and measurement of mean arterial pressure (MAP) and heart rate (HR)

The Wistar rats were anaesthetized intraperitoneally with ketamine $(45 \mathrm{mg} / \mathrm{kg})$ and xylazine $(5 \mathrm{mg} / \mathrm{kg})$. A polyethylene catheter $\left(\mathrm{PE}_{10}\right.$ connected to $\mathrm{PE}_{50}$ - Intramedic Polyethylene Tubing, BD Company, New Jersey, USA), filled with heparinized saline $0.15 \mathrm{~mol} / \mathrm{L}$ was inserted into the femoral artery in the direction of the abdominal aorta of the rats $(n=10)$, to record the blood pressure values. Another catheter was inserted into the femoral vein for drug administration. The catheters were passed under the skin and externalized in the dorsal region of the rats. The level of anesthesia during the surgery was monitored by the lack of reflex responses to frequent tail pinching and if necessary we reapplied the anesthesia. Animals were kept in individual cages after surgery, receiving standard chow and water ad libitum. After a recovery period of $24 \mathrm{~h}$, a pressure transducer and amplifier (ADInstruments, Melbourne, Australia) were connected to the intraarterial catheter and the pulsatile arterial pressure was recorded in conscious rats for period lasting $90 \mathrm{~min}$ for continuous recording of MAP and HR at basal conditions and during drug administration. Once animals were conscious during the experiment, we did not intubate or ventilate the animals. The exact volumes of drugs or saline injected in each animal did not exceed $0.5 \mathrm{~mL}$. The temperature control of room used for the experiment of record of blood pressure was $22-24{ }^{\circ} \mathrm{C}$.

During the experiments, the animals were kept conscious and without contention. After $30 \mathrm{~min}$ of a stabilizing period of blood pressure, intravenous in bolus injections of apocynin or diapocynin $(30 \mathrm{mg} / \mathrm{Kg}$ ) or vehicle were performed and their effects were recorded. Through LabChar7 software (ADInstruments), the variation of MAP ( $\triangle \mathrm{MAP}$ ) was calculated through the difference of values at basal conditions and of maximum hypotensive effect registered to $60 \mathrm{~min}$ after drugs administration. We also recorded the HR values. The original records of MAP in the LabChart7 software are shown as Supplementary material. Results were expressed as mean \pm standard error of the mean (SEM) values of MAP and HR.

\subsection{In vitro studies}

\subsubsection{Vascular reactivity experiments: resistance arteries rings}

Animals were anesthetized in a chamber saturated with halothane and killed by decapitation. The mesentery vascular bed was removed and placed in a petri dish containing Krebs solution (composition, in mmol/L: $\mathrm{NaCl} 130.0, \mathrm{KCl} 4.7, \mathrm{KH}_{2} \mathrm{PO}_{4} 1.2, \mathrm{MgSO}_{4} 1.2, \mathrm{NaHCO}_{3} 14.9$, $\mathrm{C}_{6} \mathrm{H}_{12} \mathrm{O}_{6} 5.5, \mathrm{CaCl}_{2}$ 1.6, $\mathrm{pH} 7.4,4^{\circ} \mathrm{C}$ ). The second and third branches of mesenteric arteries were isolated, dissected, cut into $2 \mathrm{~mm}$ rings with internal diameter less than $300 \mu \mathrm{m}$, after two tungsten wires $(40 \mu \mathrm{m})$ passed in the interior of the vessel. Then, vessels were mounted and normalized with a transmural pressure of $100 \mathrm{mmHg}$ according to Mulvany and Halpern [36]. The vessels were kept on stabilization period of $30 \mathrm{~min}$ in Krebs solution, $\mathrm{pH} 7.4,37^{\circ} \mathrm{C}$ with gas supply $95 \%$ $\mathrm{O}_{2}$ and $5 \% \mathrm{CO}_{2}$. A high concentration solution of $\mathrm{KCl}(120 \mathrm{mmol} / \mathrm{L})$ was used for stimulated the vessel for $15 \mathrm{~min}$ to test the viability of the preparations and considered viable those vessels that remained higher contraction than $10 \mathrm{mN}$. In some rings, the endothelium was removed mechanically (E-) and in others, endothelium was preserved $(\mathrm{E}+$ ). The absence of endothelium was confirmed by $10 \%$ or less of relaxation response to acetylcholine (ACh, $10 \mu \mathrm{mol} / \mathrm{L}$ ) and the presence of endothelium was defined as $70 \%$ or more of relaxation to ACh in precontracted preparations with phenylephrine (PE, $10 \mu \mathrm{mol} / \mathrm{L}$ ).

2.4.1.1. Apocynin and diapocynin effects in resistance mesenteric 
arteries. Cumulative concentration-curves for apocynin and diapocynin $(0.1 \mu \mathrm{mol} / \mathrm{L}$ to $1 \mathrm{mmol} / \mathrm{L})$ were performed in the rings $(n=5)$ with $(\mathrm{E}$ + ) or without endothelium (E-), after contraction induced by $\mathrm{PE}$ $0.1 \mu \mathrm{mol} / \mathrm{L}$.

Some separate mesenteric rings without endothelium were incubated for $30 \mathrm{~min}$ with $1 \mathrm{H}$-[1,2,4] oxadiazolo[4,3-a]quinoxalin-1-one (ODQ, $1 \mu \mathrm{mol} / \mathrm{L}$ ), a soluble guanylyl cyclase (sGC) inhibitor, or tetraethylammonium (TEA, $1 \mathrm{mmol} / \mathrm{L}$ ), a unspecific potassium channel blocker. In some mesenteric rings with endothelium, the preparations were incubated with $\mathrm{L}^{\mathrm{N}} \mathrm{N}^{\mathrm{G}}$-Nitroarginine methyl ester (L-NAME, $100 \mu \mathrm{mol} / \mathrm{L}, 30 \mathrm{~min}$ ), a NOS inhibitor. Then, rings were contracted with PE $1 \mu \mathrm{mol} / \mathrm{L}$ until the plateau of contraction and were performed cumulative concentration-curves for apocynin or diapocynin $(0.1 \mu \mathrm{mol} /$ $\mathrm{L}$ to $1 \mathrm{mmol} / \mathrm{L}$ ).

The relaxing effect of both compounds was measured from the plateau of contraction induced by PE and expressed as reverse percentage of this contraction. The negative logarithm of the concentration $\left(\mathrm{pD}_{2}\right)$ that produced half-maximal relaxation amplitude and the maximum effect $\left(E_{\max }\right)$ values were determined after logarithmic transformation of the concentration-response curves.

2.4.1.2. Time-effect curves to apocynin and diapocynin in resistance mesenteric arteries. On the plateau of PE $(100 \mu \mathrm{mol} / \mathrm{L})$ contraction, the intact rings $(n=5)$ were stimulated with $\mathrm{EC}_{50}$ (concentration that produced half-maximal relaxation amplitude) of apocynin $(10 \mu \mathrm{mol} / \mathrm{L})$ or diapocynin $(50 \mu \mathrm{mol} / \mathrm{L})$ and the relaxation effect were evaluated on $60,120,180,240$ and $300 \mathrm{~s}$ after drugs stimulation. Results were expressed as percentage of relaxation of PE contraction.

\subsubsection{Vascular reactivity experiments: thoracic aorta rings}

Thoracic aorta segments were removed, dissected and cut into $4 \mathrm{~mm}$ rings. The intact $(\mathrm{E}+)$ aortic rings were placed between two stainless steel stirrups and connected to an isometric force transducer (Letica Scientific Instruments, Barcelona, Spain). The preparations were kept in Krebs solution, $\mathrm{pH} 7.4,37{ }^{\circ} \mathrm{C}$ with gas supply $95 \% \mathrm{O}_{2}$ and $5 \% \mathrm{CO}_{2}$. The rings were stretched to a resting tension of $2 \mathrm{~g}$ during the stabilization period $(60 \mathrm{~min})$, and they were washed regularly every $20 \mathrm{~min}$. The viability of aortic rings was tested using high $\mathrm{KCl}$ solution $(120 \mathrm{mmol} /$ L). The presence of endothelium was confirmed when $70 \%$, or more, of relaxation induced by ACh $(1 \mu \mathrm{mol} / \mathrm{L})$ was observed in aortic rings contracted with PE $(0.1 \mu \mathrm{mol})$.

2.4.2.1. Apocynin and diapocynin effects in aorta rings. Apocynin and diapocynin $(100 \mu \mathrm{mol} / \mathrm{L})$ were incubated for $30 \mathrm{~min}$, and then, cumulative concentration-curves to PE $(0.1 \mathrm{nmol} / \mathrm{L}$ to $50 \mu \mathrm{mol} / \mathrm{L})$ were performed in the rings $(n=5)$. Some rings were not incubating with drugs and were used as control.

In other aortic rings, L-NAME $(100 \mu \mathrm{mol} / \mathrm{L}, 30 \mathrm{~min})$ was added in preparations in absence (control) or presence of apocynin $(100 \mu \mathrm{mol} / \mathrm{L})$ or diapocynin $(100 \mu \mathrm{mol} / \mathrm{L})$. After that, cumulative concentrationcurves to PE $(0.1 \mathrm{nmol} / \mathrm{L}$ to $50 \mu \mathrm{mol} / \mathrm{L})$ were performed.

The results were expressed as mean \pm SEM, in grams (g) of contraction, and $\mathrm{E}_{\max }$ and $\mathrm{pD}_{2}$ were determined after logarithm transformation of the concentration-response curves to $\mathrm{PE}$ in each aortic ring used.

\subsubsection{Flow cytometry experiments: aortic endothelial cells}

Thoracic aorta was isolated, dissected, cut longitudinally and maintained in modified Hanks solution (composition, in mmol/L: $\mathrm{NaCl} 120.0, \mathrm{KCl} 10.0, \mathrm{C}_{6} \mathrm{H}_{12} \mathrm{O}_{6}$ 10.0, HEPES 10.0, $\mathrm{MgCl}_{2} 1.0, \mathrm{CaCl}_{2}$ 1.6, $\left.\mathrm{NaH}_{2} \mathrm{PO}_{4} 0.5, \mathrm{pH} 7.4,37^{\circ} \mathrm{C}\right)$. The endothelial cells were mechanically removed with suitable plastic squeegee, and then, they were suspended in $250 \mu \mathrm{L}$ of Hanks solution. Cell suspension was centrifuged (1000 rpm, $5 \mathrm{~min})$ at $37^{\circ} \mathrm{C}$.
2500 cells/aorta $(n=5)$ were incubated $(20 \mathrm{~min})$ without (blank) or with fluorescent probes: DAF-2/DA (4,5-diaminofluorescein diacetate, $10 \mu \mathrm{mol} / \mathrm{L}$ ), FLUO-3AM (4-(6-Acetoxymethoxy-2,7-dichloro-3-oxo-9xanthenyl)-4'-methyl-2,2'(ethylenedioxy)dianiline- $\mathrm{N}, \mathrm{N}, \mathrm{N}^{\prime}, \mathrm{N}^{\prime}$ -

tetraacetic acid, $5 \mu \mathrm{mol} / \mathrm{L}$ ) or DHE (dihydroethidium, $2.5 \mu \mathrm{mol} / \mathrm{L}$ ) to detect intracellular concentrations of nitric oxide (NO), calcium $\left(\mathrm{Ca}^{2+}\right)$ and reactive oxygen species (ROS), respectively. Subsequently, the cells were incubated with apocynin $(10 \mu \mathrm{mol} / \mathrm{L})$ or diapocynin $(50 \mu \mathrm{mol} / \mathrm{L})$. Using a flow cytometer (Attune ${ }^{\mathrm{TM}}$ Acoustic Focusing Cytometer, Applied Biosystems, Vic, Australia), samples were excited with a blue laser at $488 \mathrm{~nm}$ and emission at 530/30 nm, to DAF-2/DA and FLUO-3AM experiments, and with a blue laser at $488 \mathrm{~nm}$ and emission at 585/ $42 \mathrm{~nm}$, to DHE experiments. A software (Attune Cytometric Software, Applied Biosystem) analyzed the cytofluorographic tracings generated and the results were expressed as the mean values of the medians of fluorescence intensity (FI) from the cells stimulated with fluorescent probes in presence or absence of apocynin or diapocynin stimuli, according to Potje et al. [37] and Troiano et al. [38]. The obtained values were analyzed and compared between cells incubated with apocynin or diapocynin.

\subsection{Preparation and analysis of diapocynin}

Diapocynin was prepared as previously described, with modifications [39]. Apocynin $(3.0 \mathrm{~g}, 18 \mathrm{mmol})$ was dissolved in $400 \mathrm{~mL}$ of hot water. Then, the heating was turned off and ammonium iron(II) sulphate hexahydrate $(354 \mathrm{mg}, 0.9 \mathrm{mmol})$ and potassium persulphate $(2.4 \mathrm{~g}, 9.0 \mathrm{mmol})$ were added and stirred for additional $30 \mathrm{~min}$. The precipitated was filtered and washed with cold water. The product was re-dissolved by adding sodium hydroxide $(100 \mathrm{~mL}, 4 \mathrm{~mol} / \mathrm{L})$ and filtered. The brown solution was acidified by adding hydrochloric acid $(100 \mathrm{~mL}, 4 \mathrm{~mol} / \mathrm{L})$ and the precipitate was filtered and washed with cold water. The product was dried in a vacuum over phosphorus pentoxide, yielding $1.7 \mathrm{~g}$ (57\%) of a yellow solid. The product was characterized by NMR spectra $\left(\mathrm{CDCl}_{3}\right.$ and $\mathrm{DMSO}-\mathrm{D}_{6}$ solutions) using tetramethylsilane as an internal reference for $1 \mathrm{H}$ and DMSO- $\mathrm{D}_{6}$ as an internal reference for $13 \mathrm{C}$ (Bruker DRX 400 spectrometer, MA, USA). ${ }^{1} \mathrm{H}$ NMR (400 MHz, CDCl3) d (ppm): 7.58-7.64 (m, 4H), 6.32 (s, $2 \mathrm{OH}$ ), 4.02 (s, 6H), 2.58 (s, 6H). ${ }^{1} \mathrm{H}$ NMR (400 MHz, DMSO-D 6 ) d (ppm): 9.48 (s, $2 \mathrm{OH}), 7.48$ (d, $2 \mathrm{H}, \mathrm{J}=2.0 \mathrm{~Hz}$ ), 7.46 (d, 2H, J=2.0 Hz), 3.91 (s, 6H), 2.51 (s, 6H). ${ }^{13} \mathrm{C}$ NMR (100 MHz, DMSO-D $)$ d (ppm): $196.2(2 \mathrm{C}=\mathrm{O})$, 149.1 (2 C), 147.4 (2 C), 127.9 (2 C), 125.3 (2 CH), 124.4 (2 C), 109.6 (2 $\mathrm{CH}), 56.0\left(2 \mathrm{CH}_{3}\right), 26.3\left(2 \mathrm{CH}_{3}\right)$.

\subsection{Drugs and reagents}

Apocynin (4'-Hydroxy-3'-methoxyacetophenone, A10809), PE (P6126), ODQ (1H-[1,2,4] oxadiazolo[4,3-a]quinoxalin-1-one, O3636), TEA (tetraethylammonium, T2265), L-NAME (L-N ${ }^{\mathrm{G}}$-Nitroarginine methyl ester, N5751), ACh (A6625), DAF-2/DA (D2813), DHE (D37291) and FLUO3-AM (73881), potassium persulphate and ammonium iron (II) sulphate hexahydrate were purchased from SigmaAldrich Chemical Co. (St. Louis, MO, USA). Diapocynin was synthesized in chemical laboratory coordinated by Professor Valdecir F. Ximenes, School of Sciences of Bauru, UNESP, Brazil. Impure considerate compounds have a several melting and boiling points, as the different substances they contain melt or boil at different temperatures. On the other hand, pure compounds have definite melting points and boiling points. According to manufacturer information, apocynin has a purity of $\geq 98 \%$ and diapocynin has a purity of $\geq 99 \%$ [40].

$\mathrm{PE}, \mathrm{ACh}$, L-NAME were prepared in deionized water. Apocynin, ODQ, TEA, DAF-2DA, DHE and FLUO-3AM were prepared in dimethylsulfoxide (DMSO). The concentration of DMSO did not exceed $0.5 \%$ in all in vitro experiments. Apocynin and diapocynin prepared in DMSO solution were diluted in saline $(0.15 \mathrm{~mol} / \mathrm{L})$ for in vivo experiments (vehicle). 
<smiles>COc1cc(C(C)=O)ccc1O</smiles>

Apocynin
B<smiles>COc1cc(C(C)=O)cc(-c2cc(C(C)=O)cc(OC)c2O)c1O</smiles>

Fig. 1. Chemical structure of (A) Apocynin and (B) Diapocynin.

The chemical structures of apocynin and diapocynin were demonstrated in Fig. 1A and B, respectively.

\subsection{Statistical analysis}

All results were expressed as mean \pm SEM and $n$ represents the number of animals, aortic or mesenteric rings used in the experiments. The statistical analysis of the results was performed using one-way analysis of variance (ANOVA) followed by Tukey's or Dunnett's post-test or Student's $t$-test when appropriate, using GraphPad Prism 3.0 (GraphPad Software Corporation, La Jolla, CA, USA). Differences were significant when $\mathrm{p}<0.05$.

\section{Results}

\subsection{The total antioxidant capacity of diapocynin was higher than} antioxidant capacity of apocynin

We observed that apocynin and diapocynin was able to reduce the $\mathrm{Fe}^{3+}$ TPTZ complex to $\mathrm{Fe}^{2+}$ in acidic medium in a concentrationdependent way. The antioxidant capacity of several concentrations tested of diapocynin $(10 \mu \mathrm{mol} / \mathrm{L}: \quad 0.118 ; 100 \mu \mathrm{mol} / \mathrm{L}: 0.953$; $1000 \mu \mathrm{mol} / \mathrm{L}: 3.937$ in $\mathrm{mmol} / \mathrm{g} / \mathrm{FeSO}_{4}$ ) were significantly higher than the antioxidant capacity of apocynin $(10 \mu \mathrm{mol} / \mathrm{L}: 0.050 ; 100 \mu \mathrm{mol} / \mathrm{L}$ : 0.348; $1000 \mu \mathrm{mol} / \mathrm{L}: 1,793$, in $\mathrm{mmol} / \mathrm{g} / \mathrm{FeSO}_{4}$ ) (Fig. 2).

\subsection{Apocynin and diapocynin induced hypotensive effect in Wistar rats}

The in bolus administration of apocynin and diapocynin $(30 \mathrm{mg} / \mathrm{Kg}$, i.v) induced a hypotensive effect, but only apocynin promoted a long lasting effect (Fig. 3A). The greatest hypotensive effect of apocynin (10 min: $-6.190 \pm 0.33 ; 20 \mathrm{~min}:-11.38 \pm 0.16 ; 30 \mathrm{~min}:-11.63 \pm$

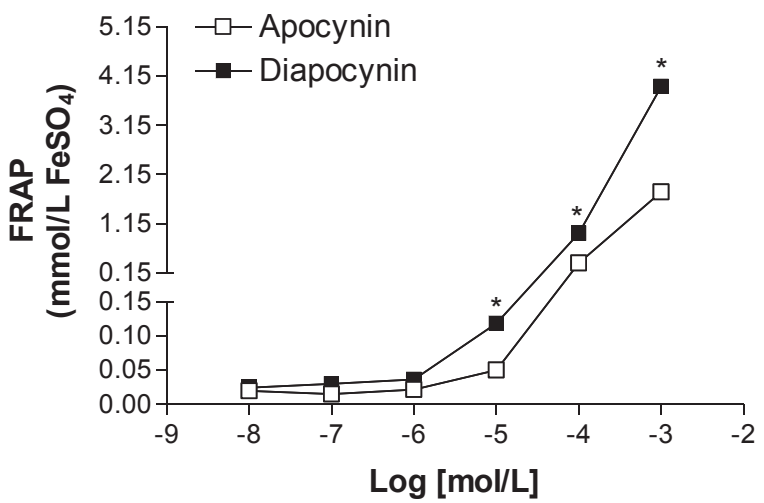

Fig. 2. Antioxidant capacity of Apocynin and Diapocynin in the concentrations of 0.01 , $0.1,1,10,100$ and $1000 \mu \mathrm{mol} / \mathrm{L}$. ${ }^{*} \mathrm{p}<0.05$ between Apocynin versus Diapocynin at different concentrations.
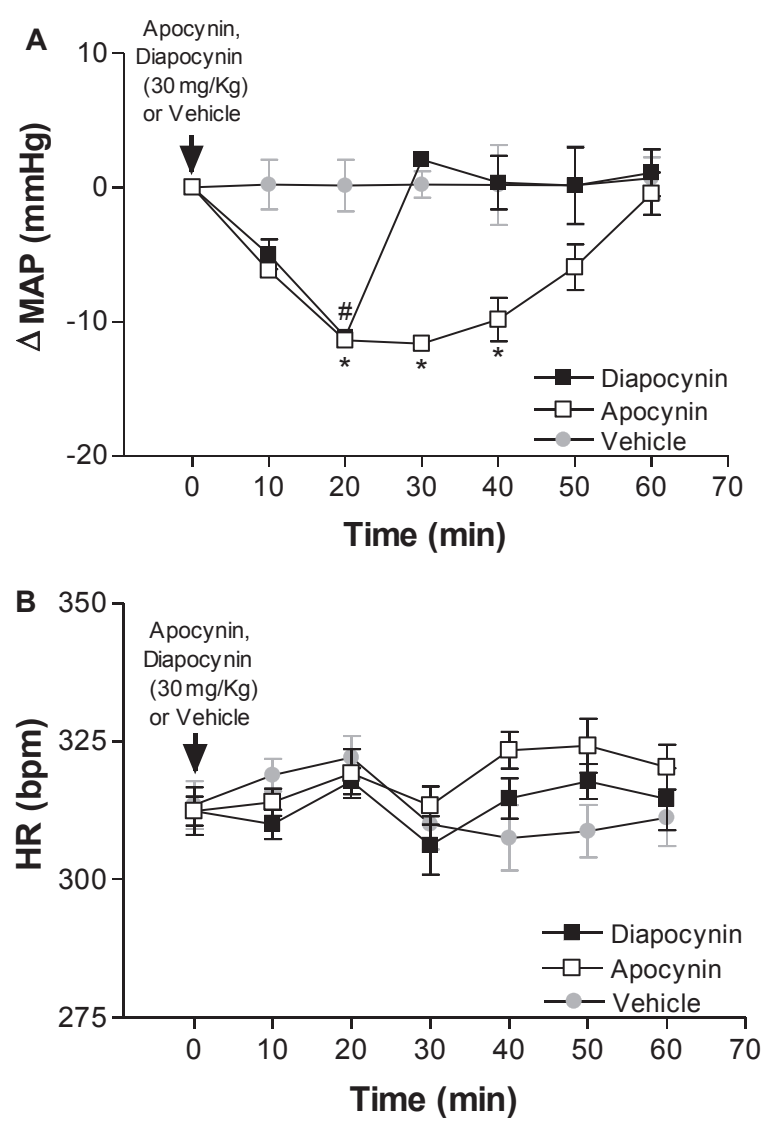

Fig. 3. Variation of (A) mean arterial pressure $(\triangle \mathrm{MAP}$, in $\mathrm{mmHg}$ ) and (B) heart rate (HR, in $\mathrm{bpm}$ ) at basal condition ( $0 \mathrm{~min})$ and 10, 20, 30, 40, 50 and $60 \mathrm{~min}$ after Apocynin $(30 \mathrm{mg} / \mathrm{Kg})$, Diapocynin $(30 \mathrm{mg} / \mathrm{Kg})$ or Vehicle infusion in Wistar rats $(n=5)$. Data represent mean \pm SEM of the experiments and $n$ represents the number of animals used. ${ }^{*} \mathrm{p}<0.05$ at 20,30 and $40 \mathrm{~min}$ after Apocynin infusion versus vehicle, ${ }^{*} \mathrm{p}<0.05$ at 20 min after Diapocynin infusion versus vehicle.

0.35; 40 min: $-9.83 \pm 1.63$; $50 \mathrm{~min}:-5.93 \pm 1.70$; $60 \mathrm{~min}:-0.45 \pm$ 1.57; in mmHg, $n=5$ ) was observed until 40 min after drug administration, however diapocynin hypotensive effect was completely reverted at $30 \mathrm{~min}$ after drug administration $(10 \mathrm{~min}$ : $-4.98 \pm 1.11$; $20 \mathrm{~min}:-11.14 \pm 0.27 ; 30 \mathrm{~min}: 2.07 \pm 0.42 ; 40 \mathrm{~min}: 0.36 \pm 1.99$; $50 \mathrm{~min}:-0.13 \pm 2.84$; $60 \mathrm{~min}: 1.08 \pm 1.65$; in $\mathrm{mmHg}, n=5$ ). The vehicle did not change the values of blood pressure (10 min: $0.21 \pm$ 1.85; 20 min: $0.13 \pm 1.92$; 30 min: $0.21 \pm 0.98$; 40 min: $0.18 \pm 2.97$; 50 min: $0.15 \pm 2.93$; 60 min: $0.67 \pm 1.56$; in $\mathrm{mmHg}, n=5$ ).

Despites apocynin and diapocynin effects on blood pressure, no effects were observed on heart rate after apocynin (10 min: $314.0 \pm$ 2.47; $20 \mathrm{~min}: 319.2 \pm 4.40 ; 30 \mathrm{~min}: 313.4 \pm 3.41$; $40 \mathrm{~min}: 323.4 \pm$ 
Table 1

Effect maximum $\left(\mathrm{E}_{\max }\right)$ in percentage (\%), and negative logarithm of half-maximal relaxation $\left(\mathrm{pD}_{2}\right)$ values of concentration-response curves to apocynin and diapocynin in mesenteric rings with intact endothelium (E +) or without endothelium (E-) of Wistar rats $(n=5)$. Data represent mean \pm SEM of the experiments and $n$ represents the number of mesenteric rings used.

\begin{tabular}{llllll}
\hline & \multicolumn{3}{l}{ Apocynin } & & \multicolumn{2}{l}{ Diapocynin } \\
\cline { 2 - 3 } \cline { 5 - 6 } & $\mathrm{E}_{\max }$ & $\mathrm{pD}_{2}$ & & $\mathrm{E}_{\max }$ & $\mathrm{pD}_{2}$ \\
\hline $\mathrm{E}+$ & $98.52 \pm 1.63$ & $5.07 \pm 0.07^{*}$ & & $96.48 \pm 0.96$ & $4.53 \pm 0.14^{*}$ \\
$\mathrm{E}-$ & $101.86 \pm 2.78$ & $4.52 \pm 0.06$ & & $94.41 \pm 1.71$ & $3.97 \pm 0.03$ \\
ODQ (E-) & $79.02 \pm 5.21^{\#}$ & $3.43 \pm 0.13^{\&}$ & $82.41 \pm 3.15^{\#}$ & $3.31 \pm 0.09^{\&}$ \\
TEA (E-) & $88.14 \pm 1.67^{\#}$ & $4.00 \pm 0.11^{\&}$ & & $79.09 \pm 2.47^{\#}$ & $3.61 \pm 0.11^{\&}$ \\
L-NAME (E+) & $96.05 \pm 1.90$ & $4.55 \pm 0.05^{\%}$ & & $97.24 \pm 0.86$ & $3.94 \pm 0.09^{\%}$ \\
\hline
\end{tabular}

* $\mathrm{p}<0.05 \mathrm{pD}_{2}$ values of rings $\mathrm{E}+$ and $\mathrm{E}$ - of both drugs.

\# $\mathrm{p}<0.05 \mathrm{E}_{\max }$ values of incubation with ODQ or TEA versus $\mathrm{E}$ - curve of both drugs.

\& $\mathrm{p}<0.05 \mathrm{pD}_{2}$ values of incubation with ODQ or TEA versus $\mathrm{E}$ - curve of both drugs.

${ }^{\%} \mathrm{p}<0.05 \mathrm{pD}_{2}$ values of incubation with L-NAME versus $\mathrm{E}+$ curve of both drugs.

3.31; $50 \min 324.2 \pm 4.86 ; 60 \mathrm{~min}: 320.3 \pm 4.07 ;$ in $\mathrm{bpm}, n=5$ ), diapocynin administration (10 min: $310.0 \pm 2.64 ; 20 \mathrm{~min}: 317.8 \pm$ 2.35; $30 \mathrm{~min}: 306.2 \pm 5.29$; $40 \mathrm{~min}: 314.7 \pm 3.65$; $50 \mathrm{~min}: 317.7 \pm$ 3.16; $60 \mathrm{~min}: 314.5 \pm 5.60$; in bpm, $n=5$ ) or vehicle (10 min: $318.9 \pm$ 2.95; 20 min: $322.1 \pm 3.84$; 30 min: $310.5 \pm 4.5$; 40 min: $307.5 \pm 5.8$; 50 min: $308.7 \pm 4.7$; 60 min: $311.2 \pm 5.1$; in bpm, $n=5$ ) (Fig. $3 \mathrm{~B}$ ).

\subsection{Apocynin and diapocynin induced vasodilator effect in resistance artery of Wistar rats}

Apocynin and diapocynin promoted concentration-dependent relaxing effects in rings of the 2nd and 3rd branches of mesenteric arteries contracted with PE (Table 1). The relaxing effects were observed in rings with and without endothelium (Fig. 4A and B). In intact rings, the concentration-response curves for both drugs were shifted to the left when compared to the curves obtained in rings without endothelium, showing that the presence of endothelium improves the vasodilator effect of apocynin and diapocynin (Fig. 4C).

3.4. Relaxation induced by apocynin or diapocynin in denuded mesenteric resistance arteries from Wistar involves $s G C$ and potassium channels activation

In rings without endothelium (E-), ODQ (selective SGC inhibitor) (Fig. 5A and C) or TEA (unspecific potassium channel blocker) (Fig. 5B and $\mathrm{D}$ ) reduced the maximum relaxation and the concentrationresponse curves were shifted to the right when compared to the control curves for both drugs (Table 1).

3.5. NOS participates in relaxation induced by apocynin or diapocynin in intact mesenteric resistance arteries of Wistar

In the presence of L-NAME (non-selective NOS inhibitor), the potency of apocynin or diapocynin was decreased, but did not observed change in the maximum effect of both concentration-response curves (Fig. 6A and B).

\subsection{The relaxation effect time-dependent of apocynin was faster than diapocynin in mesenteric artery}

The half maximal effective concentration $\left(\mathrm{EC}_{50}\right)$ refers to the concentration of a drug that induces response halfway between the baseline and maximum response $\left(\mathrm{E}_{\max }\right)$ and is used to show the potency of a drug. The $\mathrm{EC}_{50}$ of apocynin $(10 \mu \mathrm{mol} / \mathrm{L})$ induced faster relaxation effects in mesenteric arteries rings when compared to the $\mathrm{EC}_{50}$ of diapocynin $(50 \mu \mathrm{mol} / \mathrm{L})$ (Fig. 7), even that diapocynin was five times more concentrate.
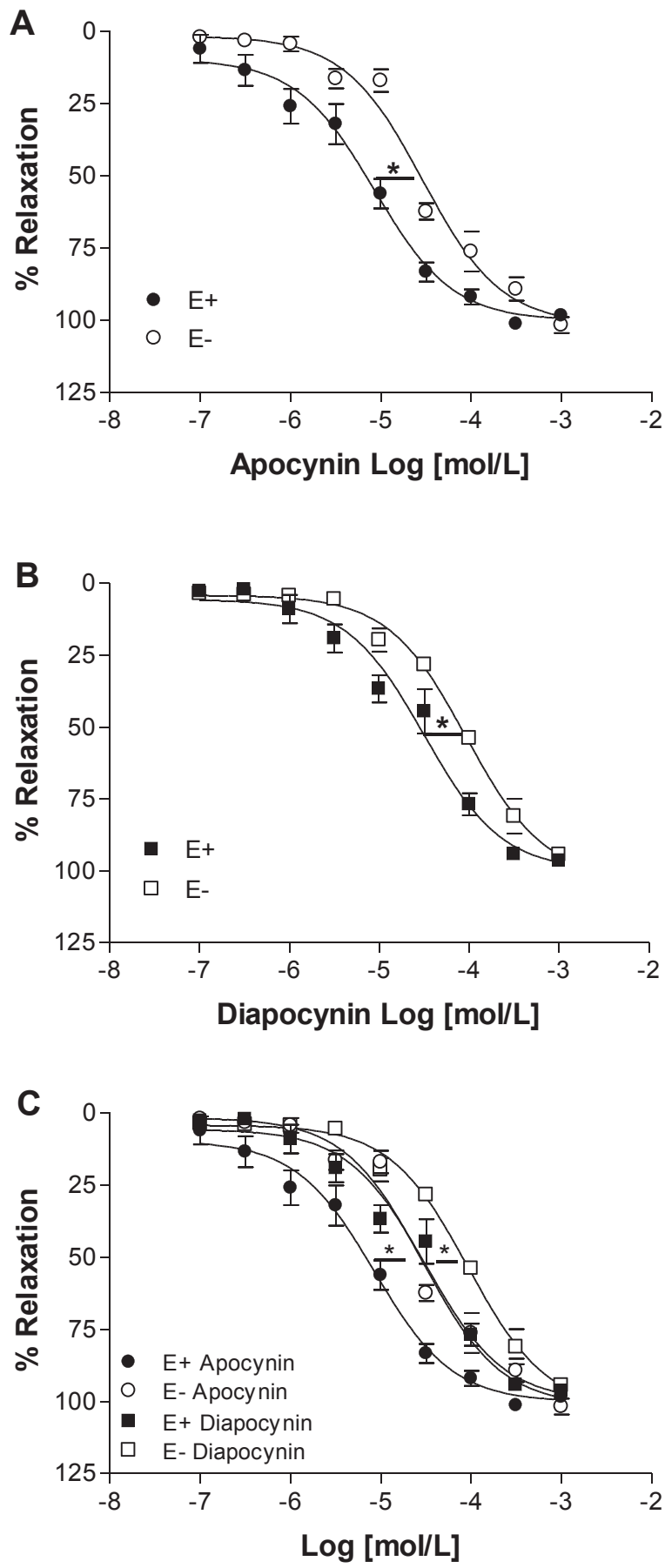

Fig. 4. Concentration-response curves to Apocynin ( $0.1 \mu \mathrm{mol} / \mathrm{L}$ to $1 \mathrm{mmol} / \mathrm{L}, \mathrm{A}, \mathrm{C})$ and Diapocynin $(0.1 \mu \mathrm{mol} / \mathrm{L}$ to $1 \mathrm{mmol} / \mathrm{L}, \mathrm{B}, \mathrm{C})$ in intact $(\mathrm{E}+$, black symbols $)$ and denuded (E-, white symbols) mesenteric rings of Wistar rats $(n=5)$. Data represent mean \pm SEM of the experiments and $n$ represents the number of mesenteric rings used. ${ }^{*} \mathrm{p}<0.05$ between $\mathrm{pD}_{2}$ values in intact ring versus in denuded ring.

3.7. Apocynin and diapocynin blunted the reactivity to phenylephrine (PE) in intact aorta

Pre-incubation of intact aortic rings with apocynin $(100 \mu \mathrm{mol} / \mathrm{L})$ or diapocynin $(100 \mu \mathrm{mol} / \mathrm{L})$ reduced the maximum effect $\left(\mathrm{E}_{\max }\right)$ of concentration-response curves to PE ( $E_{\max }$ of control curves: $1.80 \pm$ $0.08, n=5$; in presence of apocynin: $0.88 \pm 0.14, n=4$; in presence of diapocynin: $1.31 \pm 0.15, n=4$ ). Apocynin was able to reduce in $50 \%$ the $E_{\max }$ of the PE control contractions, while diapocynin reduced in $27 \%$ this effect. No alteration was observed in the $\mathrm{pD}_{2}$ values of $\mathrm{PE}$ 
A

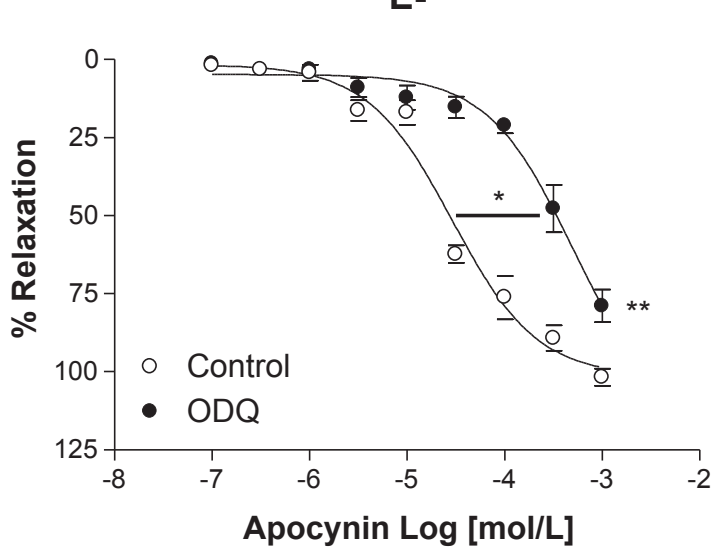

C

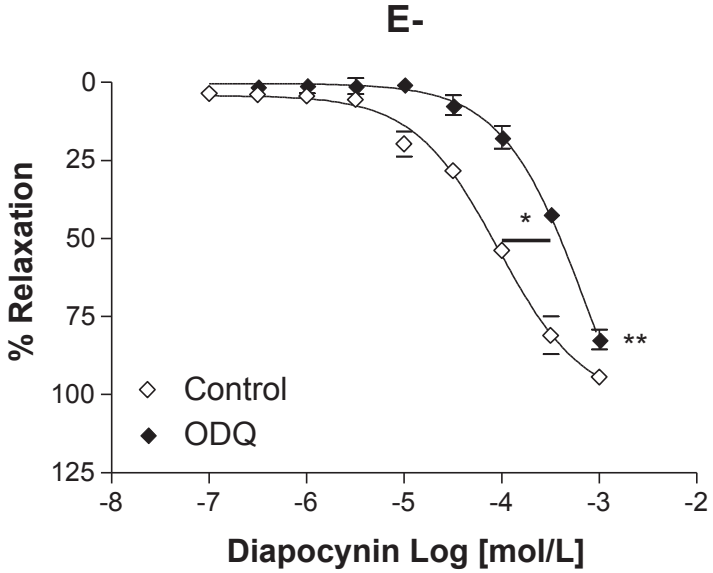

B

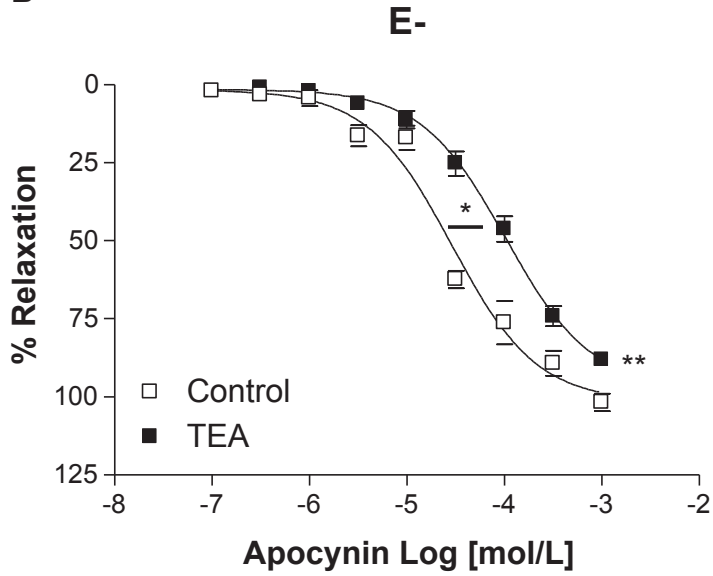

D

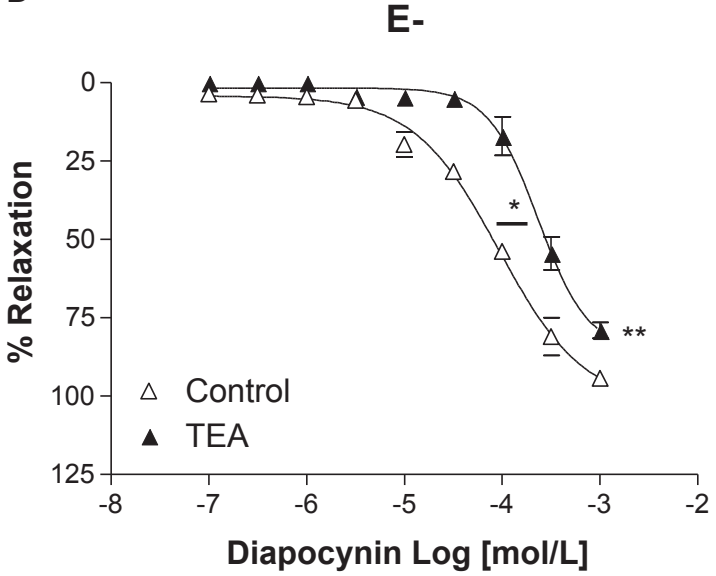

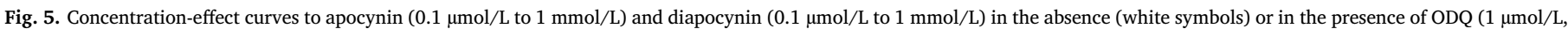

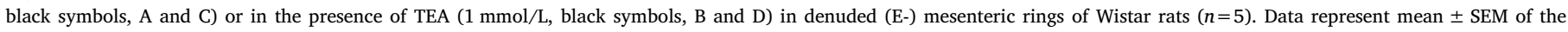

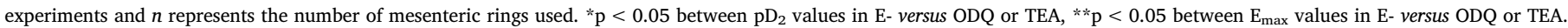

$(7.16 \pm 0.09, \mathrm{n}=5)$ in presence of apocynin $(7.20 \pm 0.16, \mathrm{n}=4)$ or diapocynin (7.35 $\pm 0.11, \mathrm{n}=4$ ) (Fig. 8).

3.8. The blocking of NOS increased the reactivity to phenylephrine (PE) in intact aortas pre-incubated with apocynin or diapocynin

L-NAME increased $\mathrm{E}_{\max }(2.59 \pm 0.13, \mathrm{n}=5)$ and $\mathrm{pD}_{2}(7.71 \pm 0.13$, $\mathrm{n}=5$ ) values of concentration-response curve to $\mathrm{PE}$ when compared to control curve (Fig. 9A). When aortic rings were incubated with diapocynin plus L-NAME, $\mathrm{E}_{\max }$ value $(2.68 \pm 0.25, \mathrm{n}=5)$ was increased twice, but not $\mathrm{pD}_{2}$ value $(7.12 \pm 0.05, \mathrm{n}=5)$, when compared to the curve incubated only in presence of diapocynin (Fig. 9B). Similarly, rings incubated with apocynin plus L-NAME showed higher $\mathrm{E}_{\max }$ value $(2.89 \pm 0.23, \mathrm{n}=5)$, but not $\mathrm{pD}_{2}$ value $(7.42 \pm 0.12, \mathrm{n}=5)$, when compared to the curve incubated only with apocynin (Fig. 9C).

3.9. Apocynin or diapocynin increased NO and reduced ROS concentrations in endothelial cells, however diapocynin did not alter $\mathrm{Ca}^{2+}$ cytosolic in these cells

NO concentration was increased in aortic endothelial cells incubated with apocynin $(7752.60 \pm 112.92 \mathrm{AU}, \mathrm{n}=5)$ or diapocynin $(6534.60 \pm 419.35 \mathrm{AU}, \mathrm{n}=5)$ when compared to NO concentration at basal conditions (5516.80 $\pm 121.55 \mathrm{AU}, \mathrm{n}=5$ ) (Fig. 10A).

A reduction in ROS concentration was observed in aortic endothelial cells incubated with apocynin $(2549.00 \pm 195.04 \mathrm{AU}, \mathrm{n}=5)$ or diapocynin $(3122.40 \pm 51.30 \mathrm{AU}, \mathrm{n}=5)$ when compared to basal ROS concentration ( $3732.60 \pm 134.76 \mathrm{AU}, \mathrm{n}=5)$ in endothelial cells from Wistar rats (Fig. 10B).

Aortic endothelial cells incubated with apocynin (6604.00 \pm 261.26, $\mathrm{n}=5$ ) showed an increased $\mathrm{Ca}^{2+}$ concentration when compared to aortic endothelial cells incubated with diapocynin (5484.20 \pm 130.48 AU, $n=5)$ or not incubated $(5331.80 \pm 163.64 \mathrm{AU}, \mathrm{n}=5)$ of Wistar rats (Fig. 10C). There was no difference in $\mathrm{Ca}^{2+}$ concentration between aortic endothelial cells at basal or incubated with diapocynin.

\section{Discussion}

This present study shows, for the first time, the hypotensive and vasodilator effects of diapocynin in normotensive Wistar rats. The main findings of this study are: (I) diapocynin shows a higher antioxidant capacity than apocynin; (II) both drugs, apocynin and diapocynin, induced hypotensive effect without changing the heart rate; (III) diapocynin was less potent than apocynin as inductor of vasodilatation in resistance mesenteric arteries; (IV) the relaxation induced by apocynin or diapocynin involves sGC and potassium channels in vascular smooth muscle cells; (V) NOS participates of relaxation induced by apocynin or diapocynin in intact mesenteric rings; (VI) apocynin and diapocynin increased NO and decreased ROS levels in endothelial cells, however only apocynin increased calcium concentration in these cells.

Diapocynin and apocynin show low solubility in deionized water, but they are soluble in dimethylsulfoxide (DMSO; diapocynin: $5.5 \mathrm{mg}$ / $\mathrm{mL}$; apocynin: $33 \mathrm{mg} / \mathrm{mL}$ ). However, just apocynin is soluble in ethanol 
A

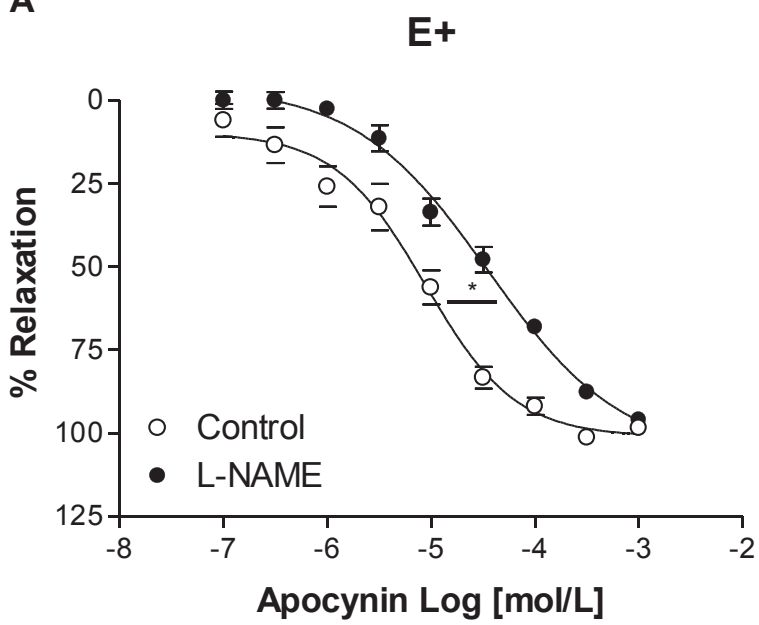

B<smiles>[12BH2-]</smiles>

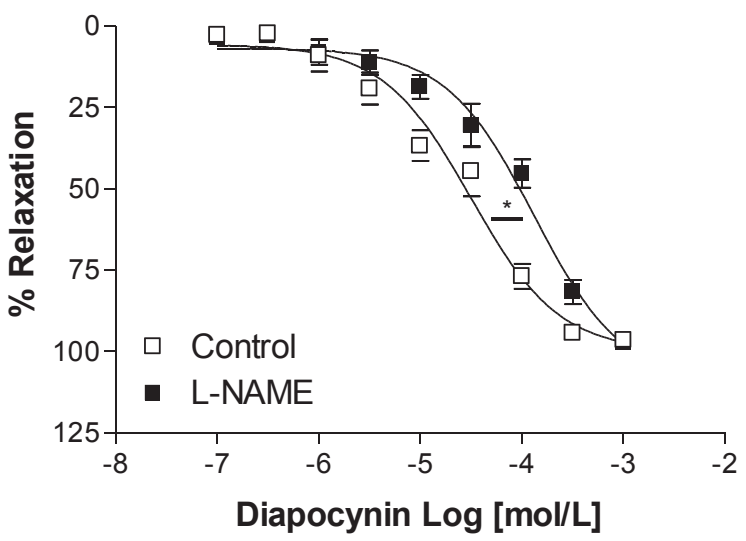

Fig. 6. Concentration-effect curves to (A) apocynin $(0.1 \mu \mathrm{mol} / \mathrm{L}$ to $1 \mathrm{mmol} / \mathrm{L})$ and (B) diapocynin $(0.1 \mu \mathrm{mol} / \mathrm{L}$ to $1 \mathrm{mmol} / \mathrm{L}$ ) in the absence (white symbols) or in the presence of L-NAME $(100 \mu \mathrm{mol} / \mathrm{L}$, black symbols) in intact endothelium $(\mathrm{E}+)$ mesenteric rings of Wistar rats $(n=5)$. Data represent mean \pm SEM of the experiments and $n$ represents the number of mesenteric rings used. ${ }^{*} \mathrm{p}<0.05$ between $\mathrm{pD}_{2}$ values in $\mathrm{E}+$ versus $\mathrm{E}++\mathrm{L}$ NAME.

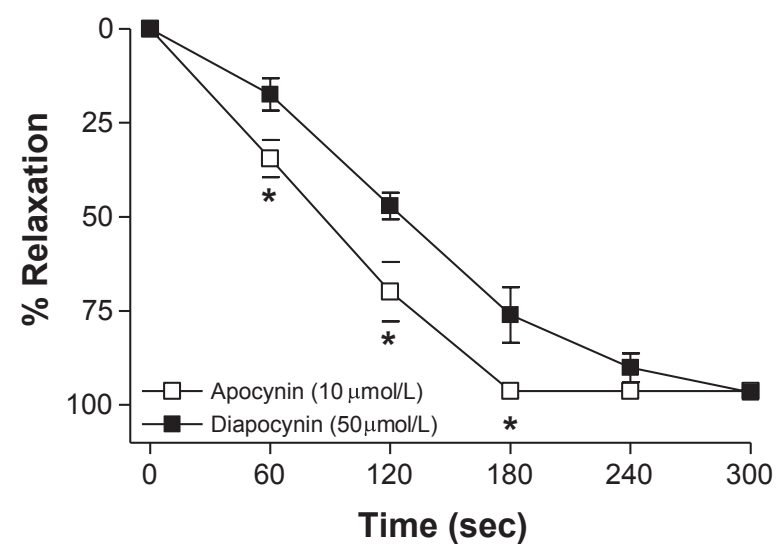

Fig. 7. Time-response curves to $\mathrm{EC}_{50}$ of Apocynin ( $10 \mu \mathrm{mol} / \mathrm{L}$, black squares) and $\mathrm{EC}_{50}$ of Diapocynin $(50 \mu \mathrm{mol} / \mathrm{L}$, white squares) at $60,120,180,240$ and $300 \mathrm{~s}$ in mesenteric rings of Wistar rats $(n=5)$. Data represent mean \pm SEM of the experiments and $n$ represents the number of mesenteric rings used. ${ }^{*} \mathrm{p}<0.05$ relaxation effects of Apocynin versus Diapocynin at 60, 120 and $180 \mathrm{~s}$.

(20 mg/mL) $[40,41]$. The log of the octanol/water partition coefficient ( $\log \mathrm{P})$ is a parameter for the estimation of molecular lipophilicity of chemical compounds, that is, the ability to pass through a cell

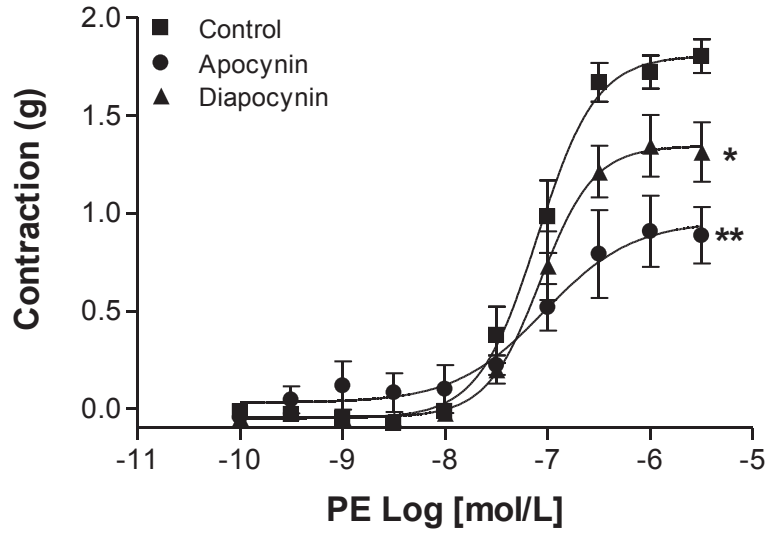

Fig. 8. Concentration-response curves to phenylephrine (PE, $0.1 \mathrm{nmol} / \mathrm{L}$ to $50 \mu \mathrm{mol} / \mathrm{L}$ ) in absence (square, control curve), in presence of Apocynin $(100 \mu \mathrm{mol} / \mathrm{L}$, circle) or Diapocynin $(100 \mu \mathrm{mol} / \mathrm{L}$, triangle) in intact aortic rings of Wistar rats $(n=5)$. Data represent mean \pm SEM of the experiments and $n$ represents the number of aortic rings used. * $\mathrm{p}<0.05 \mathrm{E}_{\max }$ of PE in presence of Diapocynin $v s$ control curve, ** $\mathrm{p}<0.001 \mathrm{E}_{\max }$ of PE in presence of Apocynin versus control curve.

membrane and can provide their pharmacokinetic properties [42]. The values of $\log \mathrm{P}$ for apocynin is 1.01 and 1.82 for diapocynin [40], this means diapocynin has more ability to cross cell membrane than apocynin.

Antioxidant capacity is the ability that a specific molecule has to neutralize free radicals by accepting or donating electron(s) to eliminate the unpaired condition of radical [43]. In this regard, previous in vitro studies demonstrated that apocynin is a relatively weak free radical scavenger when compared to protocatechuic acid, an excellent antioxidant phenolic compound. On the other hand, apocynin has a high capacity as a scavenger of non-radical reactive species as $\mathrm{HOCl}$ and $\mathrm{H}_{2} \mathrm{O}_{2}$ [44]. Moreover, apocynin tested at concentration up to $20 \mu \mathrm{mol} /$ L, did not exhibit antioxidant activity [45]. In agreement, using the FRAP assay, we observed that apocynin has antioxidant capacity only at $100 \mu \mathrm{mol} / \mathrm{L}$ and $1000 \mu \mathrm{mol} / \mathrm{L}$. On the other hand, diapocynin showed higher antioxidant capacity when compared with apocynin at different concentrations $(10 \mu \mathrm{mol} / \mathrm{L}, 100 \mu \mathrm{mol} / \mathrm{L}$ and $1000 \mu \mathrm{mol} / \mathrm{L})$ (Fig. 2). These results showed that diapocynin has higher ability to neutralize free radicals than apocynin.

We tested the effects of apocynin on blood pressure previously and observed that at $30 \mathrm{mg} / \mathrm{Kg}$ dose is effective to induce hypotensive effect in female and male normotensive and spontaneously hypertensive nonanesthetized rats [37]. Doses of lower concentrations (4, 8 and $12 \mathrm{mg} /$ $\mathrm{Kg}$ ) of apocynin also induced reduction of systolic blood pressure in anesthetized spontaneously hypertensive rats [34]. However, apocynin at $200 \mu \mathrm{mol} / \mathrm{Kg}$, did not alter blood pressure [46] in DOCA-salt hypertensive rats.

As far as we know, this is the first study demonstrating that diapocynin $(30 \mathrm{mg} / \mathrm{Kg})$, was also able to induce hypotension without changing heart rate in Wistar rats. Despite diapocynin shows greater ability to cross cell membrane and higher ability to neutralize free radicals than apocynin, the hypotensive effect of diapocynin was completely abolished $30 \mathrm{~min}$ after its administration, whereas the hypotensive effect of apocynin has been maintained in long lasting period (Fig. 3).

Diapocynin and apocynin was applied intravenous, but we did not analyze the metabolization, distribution or accumulation of both compounds in biological system. Wang et al. [47] showed that $30 \mathrm{~min}$ after intraperitoneal injection of apocynin $(5 \mathrm{mg} / \mathrm{Kg}$ body weight) in adult male Sprague-Dawley rats, approximately $50 \%$ of apocynin was converted to its glycosyl derivative and was distributed in plasma, liver and brain of rats. However, there is no information about diapocynin distribution or metabolization in literature. Furthermore, diapocynin does not show toxicity data [39] and apocynin has very low 

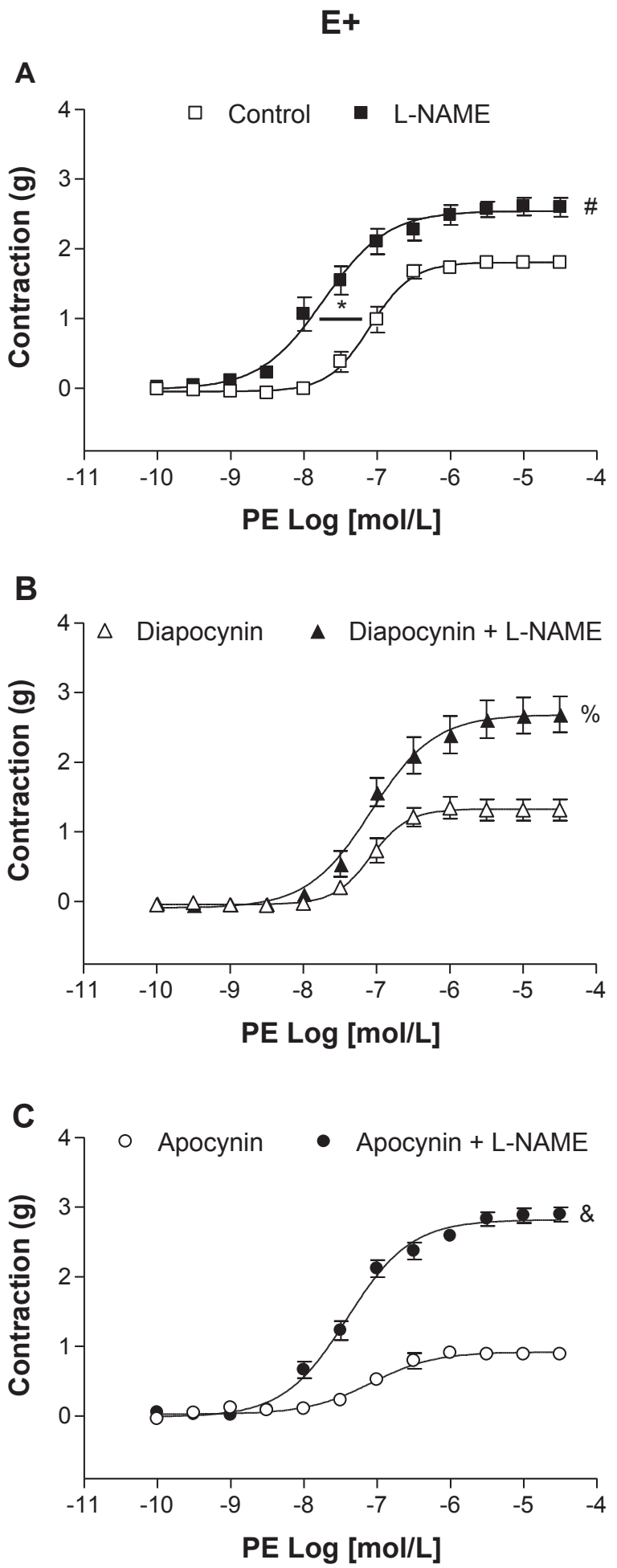

Fig. 9. Concentration-response curves to phenylephrine (PE, $0.1 \mathrm{nmol} / \mathrm{L}$ to $50 \mu \mathrm{mol} / \mathrm{L}$ ) in absence (white symbols) or presence (black symbols) of L-NAME in intact aortic rings (A) not incubated (Control) and incubated with (B) diapocynin $(100 \mu \mathrm{mol} / \mathrm{L})$ or $(\mathrm{C})$ apocynin $(100 \mu \mathrm{mol} / \mathrm{L})$ of Wistar rats $(n=5)$. Data represent mean \pm SEM of the experiments and $n$ represents the number of aortic rings used. ${ }^{*} \mathrm{p}<0.05 \mathrm{pD}_{2}$ values of control curves in presence versus absence of L-NAME, ${ }^{\#} \mathrm{p}<0.05 \mathrm{E}_{\max }$ values control curves in presence versus absence of L-NAME, ${ }^{\%} \mathrm{p}<0.05 \mathrm{E}_{\max }$ values of curves incubated with diapocynin $100 \mu \mathrm{mol} / \mathrm{L}$ in presence versus absence of L-NAME, ${ }^{\&} \mathrm{p}<0.05 \mathrm{E}_{\max }$ values of curves incubated with apocynin $100 \mu \mathrm{mol} / \mathrm{L}$ in presence versus absence of L-NAME.

toxicity $\left(\mathrm{LD}_{50}: 9 \mathrm{~g} / \mathrm{Kg}\right)[41]$.

In order to evaluate if the hypotensive effect of diapocynin could be associated to its effect on peripheral vascular resistance, we tested the
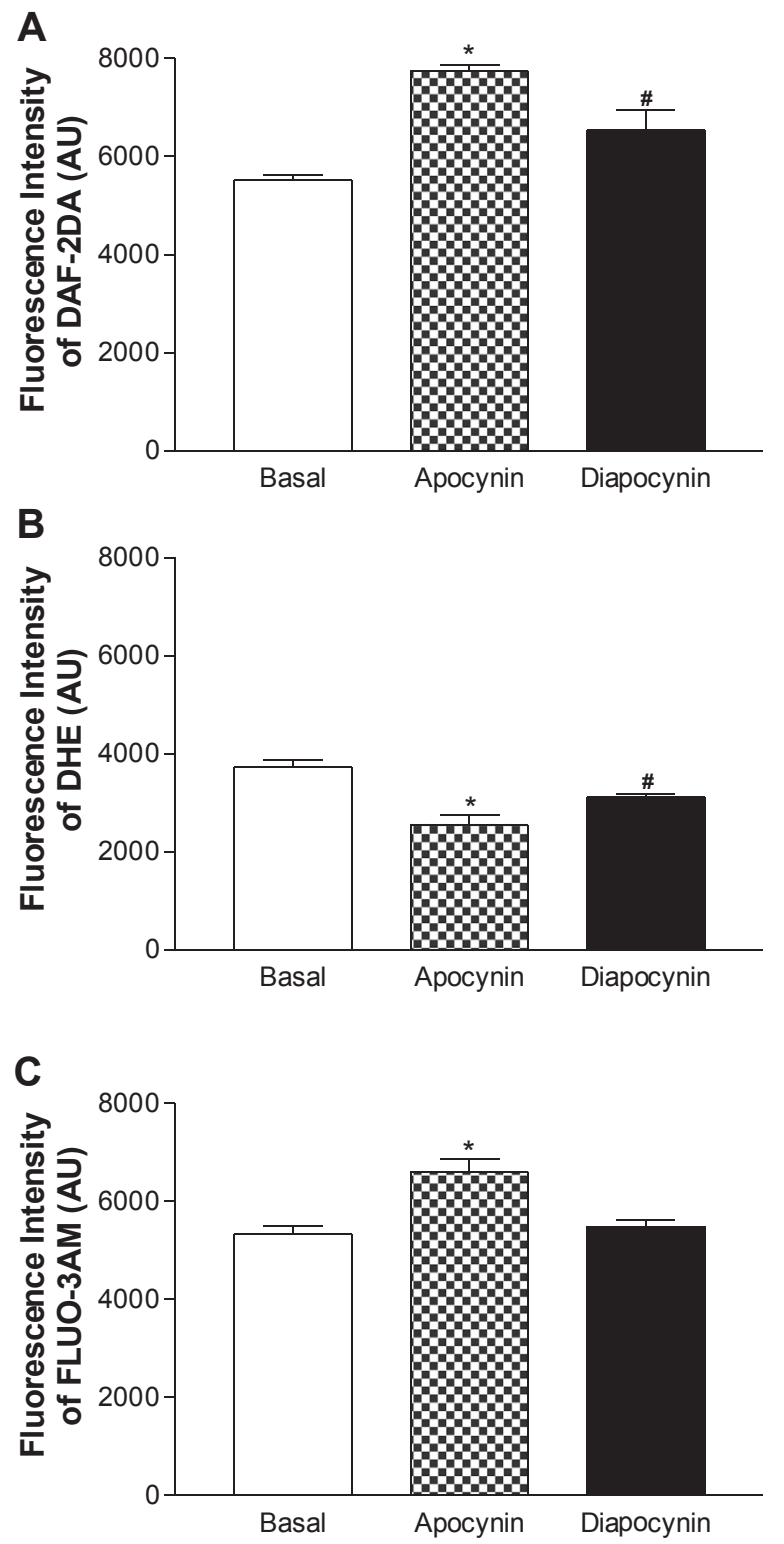

Fig. 10. Fluorescence intensity (FI, in arbitrary units) of (A) DAF-2DA, (B) DHE and (C) FLUO-3AM at basal condition (white bars) or in presence of apocynin $(10 \mu \mathrm{mol} / \mathrm{L}$, black bars) or diapocynin ( $50 \mu \mathrm{mol} / \mathrm{L}$, checkerboard bars) in aortic endothelial cells of Wistar rats $(n=5)$. Bars represent mean \pm SEM of the experiments and $n$ represents 2500 cells or events of each aortas used. ${ }^{*} \mathrm{p}<0.05$ apocynin versus basal condition, ${ }^{\#} \mathrm{p}<0.05$ diapocynin versus basal condition.

effect of this drug on vascular reactivity of mesenteric resistance arteries. Apocynin and diapocynin induced concentration-dependent relaxation in intact or denuded mesenteric artery rings, pre-contracted with phenylephrine. However, diapocynin was less potent than apocynin (Fig. 4). Furthermore, analyzing the time-course curves of both drugs, we observed that diapocynin was less effective to induced maximum relaxation within $240 \mathrm{~s}$, while apocynin needed just $180 \mathrm{~s}$ to induce the same effect (Fig. 7). The in vivo effects of apocynin and diapocynin can be associated by its effects on resistance and conductance arteries.

In vascular smooth muscle cells, the NO released by endogenous or exogenous source activates SGC, generating the second messenger cyclic guanosine monophosphate (cGMP) and that, in turn, activates protein kinase $G$ [48]. It has been reported that protein kinase $G$ can phosphorylate proteins in the sarcoplasmic reticulum that lead to activation of $\mathrm{Ca}^{2+}$-ATPase (SERCA) [49,50], potassium channels [51], and to the inhibition of inositol tri-phosphate $\left(\mathrm{IP}_{3}\right)$-mediated 
$\mathrm{Ca}^{2+}$-release [52]. All these actions lead to a decrease in intracellular calcium concentration in vascular smooth muscle cells, promoting relaxation. Our results demonstrated that ODQ (selective soluble guanylyl cyclase inhibitor) and TEA (unspecific potassium channel blocker) reduced the maximum effect and potency of apocynin and diapocynin, in denuded mesenteric arteries of Wistar (Fig. 5). This present results suggests that in Wistar mesenteric arteries without endothelium, the NO concentration increased by apocynin or diapocynin (Fig. 10A) activates sGC and can directly activate potassium channels independent of protein kinase G [53]. Moreover, in presence of endothelium, NOS participates in the relaxation induced by apocynin and diapocynin (Fig. 6). Senejoux et al. [34], demonstrated that apocynin induces vasodilation endothelium-independent through calcium mobilization and potassium-ATP channels in vascular smooth muscle cells. Moreover, relaxation induced by apocynin endotheliumdependent involved NOS [32,34] as we observed in our findings. Furthermore, Han et al. [33] demonstrated that 4-Aminopyridine (voltage-gated potassium channels blocker) attenuated apocynin-induced relaxation in aorta and abolished the increased calcium and NO concentration in endothelial cells, indicating the involvement of potassium channels in apocynin effect.

We observed that diapocynin, as apocynin, induced aorta hyporeactivity to phenylephrine in intact rings, despite the lower effect was observed with diapocynin than apocynin (Fig. 8). L-NAME reversed the aorta hyporeactivity in rings pre-incubated with apocynin or diapocynin, showing that NOS blunted the phenylephrine concentrationresponse curves in aortic rings of Wistar (Fig. 9). Silva et al. [54] demonstrated that alpha ${ }_{1}$-adrenoceptor activation contributed to the increase of eNOS activity by Serine ${ }^{1177}$ phosphorylation in intactendothelium aorta of renal hypertensive (2K-1C) and sham-operated (2K) rats, which consequently decreases PE-induced contractile response.

ROS are highly reactive metabolites of oxygen and their lifetime in biological systems can range from nanoseconds to seconds. Due their high reactivity and numerous clearance mechanisms, ROS exist in vivo in either picomolar or very low nanomolar steady-state concentrations [55]. In this way, ROS detection requires specific probes that very rapidly react with ROS to compete with antioxidants and produce stable products, which can be quantified [56]. The DHE probe can freely permeate cell membrane and is used extensively to detect ROS. However, its use is limited, once DHE can form two fluorescent products, the first one is $2-\mathrm{OH}$-ethidium $(2 \mathrm{OH}-\mathrm{E})$ that can have overlapping fluorescence and the second is ethidium (Eth) that is nonspecific oxidation product [57]. Despite its limitation, DHE is perhaps the most specific fluorescent probe for superoxide detection [58] and least problematic dye, once is retained well by cells and may even tolerate mild fixation [57]. In this way, DHE was used to evaluate ROS concentration on endothelial cells.

The vasodilator effects of apocynin were associated to its effects on NO, ROS and $\mathrm{Ca}^{+2}$ concentrations in endothelial cells. Heumüller et al. [26], observed that apocynin act as an antioxidant in vascular cells and our data showed apocynin has antioxidant capacity and can decreased ROS concentration (Fig. 10B). Furthermore, the eNOS-phosphorylation on serine1177 was stimulated by apocynin [33], suggesting that apocynin can activate eNOS and increase the NO concentration as we observed in Fig. 10A. In endothelial cells of normotensive and hypertensive male rats [32] and in pregnant and non-pregnant normotensive and hypertensive rats [38] were observed that apocynin stimulated an increase in NO concentration and decreased ROS levels. Moreover, we also observed that apocynin increased $\mathrm{Ca}^{+2}$ concentration (Fig. 10C) in endothelial cells of Wistar rats.

Our results (Fig. 10) demonstrated that diapocynin also increases NO and decreases ROS concentrations in endothelial cells, however, diapocynin did not alter the $\mathrm{Ca}^{+2}$ concentration in these cells, suggesting that distinct mechanism, less dependent of $\mathrm{Ca}^{+2}$, could be involved in vasodilator effect of diapocynin. Furthermore, it was demonstrated through FRAP assay that diapocynin shows higher antioxidant capacity than apocynin. In this way, diapocynin could oxidized the ROS, decreasing ROS concentration. Once ROS can react with NO [59] and its concentration was decreased, in the other hand, NO concentration was increased. Diapocynin effects on blood pressure and vascular reactivity could be associated to increase NO-bioavailability in endothelial cells.

Different studies have been using apocynin [32,60-64] and diapocynin $[25,27,28]$ for treatment of experimental animal models to evaluate the role of $\mathrm{NAD}(\mathrm{P}) \mathrm{H}$ oxidase enzyme and the contribution of ROS to oxidative stress and cardiovascular disease. Then, the intent of our study was elucidating the clinical pharmacology of diapocynin on vascular system and its vasodilator and hypotensive effect, once is an active dimer from apocynin and thus our data could contribute to the progress of the field for ROS study and vascular biology.

\section{Conclusion}

Taken together, these results showed, for the first time, that diapocynin can decrease blood pressure and to induce endotheliumdependent and independent vasodilation in resistance arteries of rats. The sGC, potassium channels and NOS participate to the relaxation induced by diapocynin. Despite in vitro diapocynin antioxidant effect was higher than apocynin, its efficacy on blood pressure reduction or its potency as vasodilator were reduced when compared to apocynin. Hence, these findings are additional evidence that the widespread beneficial properties of apocynin are not only related to its antioxidant activity. Finally, diapocynin, as observed to apocynin, improves NObioavailability, increasing NO and reducing ROS in aortic endothelial cells.

\section{Declaration of interest}

The authors declare that there are no conflicts of interest.

\section{Acknowledgments}

This study was supported by Grants from Fundação de Amparo à Pesquisa do Estado de São Paulo - FAPESP (Processes 2012/20398-6 and 2011/20998-0) and Conselho Nacional de Desenvolvimento Científico e Tecnológico - CNPq (Processes 141323/2013-2 and 440503/2014-0).

\section{Appendix A. Supporting information}

Supplementary data associated with this article can be found in the online version at doi:10.1016/j.freeradbiomed.2017.02.026.

\section{References}

[1] Y. Taniyama, K.K. Griendling, Reactive oxygen species in the vasculature: molecular and cellular mechanisms, Hypertension 42 (2003) 1075-1081.

[2] M. Le Bras, M.V. Clément, S. Pervaiz, C. Brenner, Reactive oxygen species and the mitochondrial signaling pathway of cell death, Histol. Histopathol. 20 (2005) 205-219.

[3] Y.J.H.J. Taverne, A.J.J.C. Bogers, D.J. Duncker, D. Merkus, Reactive oxygen species and the cardiovascular system, Oxid. Med. Cell. Longev. 2013 (2013) 1-15.

[4] Y.J. Suzuki, H.J. Forman, H.J. Sevanian, Oxidants as stimulatips of signal transduction, Free Radic. Biol. Med. 22 (1997) 269-285.

[5] K.K. Griendling, D. Sorescu, M. Ushio-Fukai, NAD(P)H oxidase: role in cardiovascular biology and disease, Circ. Res. 86 (2000) 494-501.

[6] M.S. Wolin, Interactions of oxidants with vascular signaling systems, Arterioscler. Thromb. Vasc. Biol. 20 (2000) 1430-1442.

[7] S.V. Lakshmi, G. Padmaja, P. Kuppusamy, V.K. Kutala, Oxidative stress in cardiovascular disease, Indian J. Biochem. Biophys. 46 (2009) 421-440.

[8] S.K. Wattanapitayakul, J.A. Bauer, Oxidative pathways in cardiovascular disease: roles, mechanisms, and therapeutic implications, Pharmacol. Ther. 89 (2001) 187-206.

[9] S.H. Phan, D.E. Gannon, J. Varani, U.S. Ryan, P.A. Ward, Xanthine oxidase activity in rat pulmonary artery endothelial cells and its alteration by activated neutrophils, 
Am. J. Pathol. 134 (1989) 1201-1211.

[10] I. Fleming, R. Michaelis, D. Bredenkötter, B. Fisslthaler, F. Dehghani, R.P. Brandes, R. Busse, Endothelium-derived hyperpolarizing factor synthase (Cytochrome P450 2C9) is a functionally significant source of reactive oxygen species in coronary arteries, Circ. Res. 88 (2001) 44-51.

[11] J. Vásquez-Vivar, B. Kalyanaraman, P. Martásek, N. Hogg, B.S. Masters, H. Karoui, P. Tordo, K.A. Pritchard Jr., Superoxide generation by endothelial nitric oxide synthase: the influence of cofactors, Proc. Natl. Acad. Sci. USA 95 (1998) 9220-9225.

[12] T.M. Paravicini, R.M. Touyz, NADPH oxidases, reactive oxygen species, and hypertension, Diabetes Care 31 (2008) S170-S180.

[13] B.M. Babior, J.D. Lambeth, W. Nauseef, The neutrophil NADPH oxidase, Arch. Biochem. Biophys. 397 (2002) 342-344.

[14] U. Bayraktutan, L. Blayney, A.M. Shah, molecular characterization and localization of the NAD(P)H oxidase components gp91-phox and p22-phox in endothelial cells, Arterioscler. Thromb. Vasc. Biol. 20 (2000) 1903-1911.

[15] S.S. Barbieri, V. Cavalca, S. Eligini, M. Brambilla, A. Caiani, E. Tremoli, S. Colli, Apocynin prevents cyclooxygenase 2 expression in human monocytes through NADPH oxidase and glutathione redox-dependent mechanisms, Free Radic. Biol. Med. 37 (2004) 156-165.

[16] D.K. Dang, E.J. Shin, Y. Nam, S. Ryoo, J.H. Jeong, C.G. Jang, T. Nabeshima, J.S. Hong, H.C. Kim, Apocynin prevents mitochondrial burdens, microglial activation, and pro-apoptosis induced by a toxic dose of methamphetamine in the striatum of mice via inhibition of p47phox activation by ERK, J. Neuroinflamm. 13 (2016) 1-22.

[17] L. Zhang, W. Dong, Q. Li, L. Kang, L. Zhang, Y. Lu, X. Zhai, Diphenylene iodonium and apocynin reduce the translocation and level of p47phox in PBMCs of premature infants to inhibit reactive oxygen species production, Xi Bao Yu Fen Zi Mian Yi Xue Za Zhi 32 (2016) 59-62.

[18] J. Stolk, T.J. Hiltermann, J.H. Dijkman, A.J. Verhoeven, Characteristics of the inhibition of NADPH oxidase activation in neutrophils by apocynin, a methoxysubstituted catechol, Am. J. Respir. Cell. Mol. Biol. 11 (1994) 95-102.

[19] F.P. Lafeber, C.J. Beukelman, E. van den Worm, J.L. van Roy, M.E. Vianen, J.A. van Roon, H. van Dijk, J.W. Bijlsma, Apocynin, a plant-derived, cartilage-saving drug, might be useful in the treatment of rheumatoid arthritis, Rheumatology 38 (1999) 1088-1093.

[20] D.K. Johnson, K.J. Schillinger, D.M. Kwait, C.V. Hughes, E.J. McNamara, F. Ishmael, R.W. O'Donnell, M.M. Chang, M.G. Hogg, J.S. Dordick, et al., Inhibition of NADPH oxidase activation in endothelial cells by ortho-methoxy-substituted catechols, Endothelium 9 (2002) 191-203.

[21] K. Kinkade, J. Streeter, F.J. Miller Jr., Inhibition of NADPH oxidase by apocynin attenuates progression of atherosclerosis, Int. J. Mol. Sci. 14 (2013) 17017-17028.

[22] M. Vejrazka, R. Micek, S. Stipek, Apocynin inhibits NADPH oxidase in phagocytes but stimulates ROS production in non-phagocytic cells, Biochim. Biophys. Acta 1722 (2005) 143-147.

[23] K.R. Houser, D.K. Johnson, F.T. Ishmael, Anti-inflammatory effects of methoxyphenolic compounds on human airway cells, J. Inflamm. 9 (2012) 1-12.

[24] A.C. de Almeida, M.M.S. Vilela, A. Condino-Neto, V.F. Ximenes, The importance of myeloperoxidase in apocynin-Mediated NADPH oxidase inhibition, ISRN Inflamm. 2012 (2012) 1-7.

[25] M.P. Kanegae, A. Condino-Neto, L.A. Pedroza, A.C. de Almeida, J. Rehder, L.M. da Fonseca, V.F. Ximenes, Diapocynin versus apocynin as pretranscriptional inhibitors of NADPH oxidase and cytokine production by peripheral blood mononuclear cells, Biochem. Biophys. Res. Commun. 393 (2010) 551-554.

[26] S. Heumüller, S. Wind, E. Barbosa-Sicard, H.H.H.W. Schmidt, R. Busse, K. Schröder, R.P. Brandes, Apocynin is not an inhibitor of vascular NADPH oxidases but an antioxidant, Hypertension 51 (2008) 211-217.

[27] A. Ghosh, A. Kanthasamy, J. Joseph, V. Anantharam, P. Srivastava, B.P. Dranka, B. Kalyanaraman, A.G. Kanthasamy, Anti-inflammatory and neuroprotective effects of an orally active apocynin derivative in pre-clinical models of Parkinson's disease, J. Neuroinflamm. 9 (2012) 1-16.

[28] H.M. Ismail, L. Scapozza, U.T. Ruegg, O.M. Dorchies, Diapocynin, a dimer of the NADPH oxidase inhibitor apocynin, reduces ROS production and prevents force loss in eccentrically contracting dystrophic muscle, PLoS One 9 (2014) 1-8.

[29] L. Hu, Y. Zhang, P.S. Lim, Y. Miao, C. Tan, K.U. McKenzie, C.G. Schyvens, J.A. Whitworth, Apocynin but not L-arginine prevents and reverses dexamethasoneinduced hypertension in the rat, Am. J. Hypertens. 19 (2006) 413-418.

[30] C.A. Costa, T.A. Amaral, L.C. Carvalho, D.T. Ognibene, A.F. da Silva, M.B. Moss, S.S. Valença, R.S. de Moura, A.C. Resende, Antioxidant treatment with tempol and apocynin prevents endothelial dysfunction and development of renovascular hypertension, Am. J. Hypertens. 22 (2009) 1242-1249.

[31] Y.Q. Li, X.B. Li, S.J. Guo, S.L. Chu, P.J. Gao, D.L. Zhu, W.Q. Niu, N. Jia, Apocynin attenuates oxidative stress and cardiac fibrosis in angiotensin II-induced cardiac diastolic dysfunction in mice, Acta Pharmacol. Sin. 34 (2013) 352-359.

[32] L.A. Perassa, M.E. Graton, S.R. Potje, J.A. Troiano, M.S. Lima, G.T. Vale, A.A. Pereira, A.C. Nakamune, D.H. Sumida, C.R. Tirapelli, et al., Apocynin reduces blood pressure and restores the proper function of vascular endothelium in SHR, Vasc. Pharmacol. (2016).

[33] W.Q. Han, W.T. Wong, X.Y. Tian, Y. Huang, L.Y. Wu, D.L. Zhu, P.J. Gao, Contributory role of endothelium and voltage-gated potassium channels in apocynin-induced vasorelaxations, J. Hypertens. 28 (2010) 2102-2110.

[34] F. Senejoux, C. Girard-Thernier, A. Berthelot, F. Bévalot, C. Demougeot, New insights into the mechanisms of the vasorelaxant effects of apocynin in rat thoracic aorta, Fundam. Clin. Pharmacol. 27 (2013) 262-270.

[35] I.F. Benzie, J.J. Strain, The ferric reducing ability of plasma (FRAP) as a measure of "antioxidant power": the FRAP assay, Anal. Biochem. 15 (1996) 70-76.

[36] M.J. Mulvany, W. Halpern, Contractile properties of small arterial resistance vessels in spontaneously hypertensive and normotensive rats, Circ. Res. 41 (1977) 19-26.

[37] S.R. Potje, F.C. Munhoz, L.A. Perassa, M.E. Graton, A.A. Pereira, A.C. Nakamune, R.S. da Silva, L.M. Bendhack, D.H. Sumida, C. Antoniali, Mechanisms underlying the hypotensive and vasodilator effects of Ru(terpy)(bdq)NO]( $\left.{ }^{3+}\right)$, a nitric oxide donor, differ between normotensive and spontaneously hypertensive rats, Eur. J. Pharmacol. 15 (2014) 222-229.

[38] J.A. Troiano, S.R. Potje, M.E. Graton, P. Cavalari, A.A. Pereira, G.T. Vale, A.C. Nakamune, D.H. Sumida, C.R. Tirapelli, C. Antoniali, Decreased reactive oxygen species production and NOX1, NOX2, NOX4 expressions contribute to hyporeactivity to phenylephrine in aortas of pregnant SHR, Life Sci. 144 (2016) $178-184$.

[39] M.S. Dasari, K.M. Richards, M.L. Alt, C.F.P. Crawford, A. Schleiden, J. Ingram, Synthesis of diapocynin, J. Chem. Educ. 85 (2008) 411-412.

[40] R. Luchtefeld, R. Luo, K. Stine, M.L. Alt, P.A. Chernovitz, R.E. Smith, Dose formulation and analysis of diapocynin, J. Agric. Food Chem. 56 (2008) 301-306.

[41] J. Stefanska, R. Pawliczak, Apocynin: molecular aptitudes, Mediat. Inflamm. 2008 (2008) $1-11$.

[42] J. Sangster, Octanol Water Partition Coefficients: Fundamentals and Physical Chemistry, John Wiley, New York, 1997, pp. 12-13.

[43] J.M. Lü, P.H. Lin, Q. Yao, C. Chen, Chemical and molecular mechanisms of antioxidants: experimental approaches and model systems, J. Cell. Mol. Med. 14 (2010) 840-860.

[44] M.S. Petrônio, M.L. Zeraik, L.M. Fonseca, V.F. Ximenes, Apocynin: chemical and biophysical properties of a NADPH oxidase inhibitor, Molecules 18 (2013) 2821-2839.

[45] S.P. Wong, V.H. Fong, A. Vieira, Activities of apocynin in cytotoxicity assays of potential pathological relevance, Biomed. Pharmacother. 76 (2015) 6-10.

[46] H. Xu, G.D. Fink, J.J. Galligan, Tempol lowers blood pressure and sympathetic nerve activity but not vascular O2- in DOCA-salt rats, Hypertension 43 (2004) 329-334.

[47] O. Wang, R.E. Smith, R. Luchtefeld, A.Y. Sun, A. Simonvi, R. Luo, G.Y. Sun, Bioavailability of apocynin through its conversion to glycoconjugate but not to diapocynin, Phytomedicine 15 (2008) 496-503.

[48] L.J. Ignarro, G. Cirino, A. Casini, C. Napoli, Nitric oxide as a signaling molecule in the vascular system: an overview, J. Cardiovasc. Pharmacol. 34 (1999) 879-886.

[49] T.L. Cornwell, K.B. Pryzwansky, T.A. Wyatt, T.M. Lincoln, Regulation of sarcoplasmic reticulum protein phosphorylation by localized cyclic GMP-dependent protein kinase in vascular smooth muscle cells, Mol. Pharmacol. 40 (1991) 923-931.

[50] H.K. Simmerman, L.R. Jones, Phospholamban: protein structure, mechanism of action, and role in cardiac function, Physiol. Rev. 78 (1998) 921-947.

[51] M. Sausbier, R. Schubert, V. Voigt, C. Hirneiss, A. Pfeifer, M. Korth, T. Kleppisch, P. Ruth, F. Hofmann, Mechanisms of NO/cGMP-dependent vasorelaxation, Circ. Res. 87 (2000) 825-830.

[52] J. Schlossmann, A. Ammendola, K. Ashman, X. Zong, A. Huber, G. Neubauer, G.X. Wang, H.D. Allescher, M. Korth, M. Wilm, et al., Regulation of intracellular calcium by a signalling complex of IRAG, IP3 receptor and cGMP kinase Ibeta, Nature 404 (2000) 197-201.

[53] V.M. Bolotina, S. Najibi, J.J. Palacino, P.J. Pagano, R.A. Cohen, Nitric oxide directly activates calcium-dependent potassium channels in vascular smooth muscle, Nature 368 (1994) 850-853.

[54] B.R. Silva, L. Pernomian, M.D. Grando, L.M. Bendhack, Phenylephrine activates eNOS Ser1177 phosphorylation and nitric oxide signaling in renal hypertensive rat aorta, Eur. J. Pharmacol. 738 (2014) 192-199.

[55] E. Cadenas, K.J. Davies, Mitochondrial free radical generation, oxidative stress, and aging, Free Radic. Biol. Med. 29 (2000) 222-230.

[56] S.I. Dikalov, D.G. Harrison, Methods for detection of mitochondrial and cellular reactive oxygen species, Antioxid. Redox Signal. 20 (2014) 372-382.

[57] E. Owusu-Ansah, A. Yavari, U. Banerjee, A protocol for in vivo detection of reactive oxygen species, Protoc. Exch. (2008).

[58] P. Wardman, Fluorescent and luminescent probes for measurement of oxidative and nitrosative species in cells and tissues: progress, pitfalls and prospects, Free Radic. Biol. Med. 43 (2007) 995-1022.

[59] D. Salvemini, Z.Q. Wang, M.K. Stern, M.G. Currie, T.P. Misko, Peroxynitrite decomposition catalysts: therapeutics for peroxynitrite-mediated pathology, Proc. Natl. Acad. Sci. USA 95 (1998) 2659-2663.

[60] A. Virdis, M.F. Neves, F. Amiri, R.M. Touyz, E.L. Schiffrin, Role of NAD(P)H oxidase on vascular alterations in angiotensin II-infused mice, J. Hypertens. 22 (2004) 535-542.

[61] A. Paliege, A. Pasumarthy, D. Mizel, T. Yang, J. Schnermann, S. Bachmann, Effect of apocynin treatment on renal expression of COX-2, NOS1, and renin in Wistar-Kyoto and spontaneously hypertensive rats, Am. J. Physiol. Regul. Integr. Comp. Physiol. 290 (2006) R694-R700.

[62] T. Kahles, P. Luedike, M. Endres, H.J. Galla, H. Steinmetz, R. Busse, T. NeumannHaefelin, R.P. Brandes, NADPH oxidase plays a central role in blood-brain barrier damage in experimental stroke, Stroke 38 (2007) 3000-3006.

[63] O. Pechánová, L. Jendeková, L.S. Vranková, Effect of chronic apocynin treatment on nitric oxide and reactive oxygen species production in borderline and spontaneous hypertension, Pharmacol. Rep. 61 (2009) 116-122.

[64] R. Ciarcia, S. Damiano, C. Panico, R. Scanni, F. Fiorito, S. Florio, J.W. Welch, Apocynin activity in spontaneously hypertensive rats (SHR): preliminary studies in vivo, Vet. Res. Commun. 34 (2010) S83-S86. 